\title{
DÊIXIS DE GÊNERO EM YAATHE, LÍNGUA INDÍGENA BRASILEIRA (MACRO-JÊ)
}

\section{Januacele da Costa ${ }^{\star}$ Fábia Pereira da Silva ${ }^{\star \star}$}

If cultural practices are those meaningful practices through which humans in relationships sustain ongoing histories of social structural coupling, then foremost among those must be linguistic practices. What people do incessantly in every known society is talk. Linguistic practices are the most pervasive way in which humans make meanings and sustain social systems; they do not exhaust human cultural practices, but are clearly primary among them. Humans could be succinctly defined as social beings encultured through language. (FOLLEY, 1997, p. 24).

Resumo: Neste artigo, aplicamos os pressupostos do Funcionalismo à análise de formas de fala masculina e feminina (Dêixis de gênero) utilizadas por falantes da língua Yaathe, a língua nativa dos índios Fulni-ô. Em Yaathe, fala masculina e fala feminina apresentam diferenças nos níveis do léxico livre e na morfologia presa. A descrição que fazemos aqui é ainda preliminar, de modo que o objetivo é apenas dar notícia do fenômeno observado.

Palavras-chave: Língua Indígena. Funcionalismo. Dêixis de gênero.

\section{Funcionalismo em linguística descritiva}

Procurando corresponder ao tema deste número da Revista Leitura, Funcionalismos, justificamos a inclusão do nosso artigo expondo brevemente alguns dos pressupostos

\footnotetext{
Professora e pesquisadora do Programa de Pós-Graduaçāo em Letras e Lingüística da Faculdade de Letras da Universidade Federal de Alagoas (UFAL).

* Aluna do curso de Letras da Faculdade de Letras da Universidade Federal de Alagoas (UFAL).
} 
essenciais de uma visão funcionalista da linguagem e da sua utilização pelo lingüista descritivista.

Um ponto crucial dessa linha de estudos é a leve revisão do conceito saussureano de signo lingüístico. Muito no mesmo sentido de Saussure (1916), o signo lingüístico é ainda tomado considerandose uma interdependência entre significado e forma (significado e significante). O significado é visto não apenas, porém, como o valor semântico, por assim dizer, inerente, mas como para que é usado. Ou seja, o que é significado em Saussure, para o funcionalista de que estamos falando é uso. A linguagem é usada para significar, expressar, codificar, representar ou referir a outras coisas (PAYNE, 1997, p. 7). Nesse sentido, o laço entre significante e significado é intencional: ele não pode ser nem aleatório - porque a língua é um sistema simbólico - nem rígido - porque a língua não é um sistema simbólico ideal (como as "linguagens" de computadores devem ser, por exemplo). Por isso, "(...) It is direct enough to allow communication, but flexible enough to allow for creativity, variation and change" (PAYNE, 1997, p. 6).

Sendo assim, as abordagens funcionais assumem que estratégias lexicais, morfológicas e perifrásticas estão disponíveis e são relevantes para muitas e diferentes tarefas funcionais na linguagem e que algumas tarefas que são realizadas por uma estratégia em uma língua podem ser realizadas por uma das outras estratégias em outra língua. Para o lingüista descritivista que opta por uma abordagem funcional, sua conceitualização e descrição da língua compreende uma análise das suas propriedades formais e a interpretação dessas propriedades, considerando-se o caráter essencialmente humano e comunicativo da linguagem. Dito de outro modo, ao lingüista descritivista que comunga os pressupostos funcionalistas interessa não apenas a estrutura formal das palavras e sentenças, mas também o uso, que é determinado pelas situações comunicativas de acordo com aspectos sócio-culturais da comunidade de fala. 
Assim, neste artigo, estaremos discutindo um aspecto da estrutura linguística de uma língua indígena brasileira na sua relação com um aspecto da sociedade que utiliza essa língua, a distinção de gênero, mais especificamente a dêixis de gênero. O pressuposto é o de que a diferença de sexo, do modo como é tratada pela sociedade, está refletida na estrutura morfossintática e no léxico.

\section{Distinções de gênero}

Uma importante distinção encontrada em todas as línguas do mundo é a distinção de gênero. Essa distinção, em algumas línguas, pode vir expressa pela escolha das expressões linguísticas, nos usos discursivos, nas estratégias lingüísticas utilizadas, em termos de instâncias e relações sociais, que identificam o gênero do falante. Dessa perspectiva, a distinção de gênero é um tema que interessa à Lingüística Antropológica e a uma das suas sub-áreas, a Etnografia da Fala. Embora ela seja uma perspectiva interessante quando se trata de estudar a distinção de gênero - mas não da categoria gramatical, um tipo de classificação nominal, que divide os nomes de uma língua em masculino, feminino e neutro - neste artigo trataremos especificamente da distinção que pode ser chamada dêixis de gênero, que se costuma encontrar expressa em morfemas especiais da língua e que indicam diretamente o sexo do falante e/ou do ouvinte.

A distinção de gênero que se realiza nas línguas e pode ser considerada como fazendo parte de um sistema de classificação nominal difere da distinção de dêxixis de gênero, apesar de ser expressa do mesmo modo pelo léxico - tanto em formas livres, léxico propriamente dito, como em formas presas, na morfologia, ambas segmentáveis e usadas em contextos fixos. De acordo com Payne (1997, p. 107),

A noun class, gender, or grammatical gender is the grammatical classification of noun, pronouns, and others referential devices. Often such a system correlates with some extralinguistic grouping, such 
as human vs. non-human or female vs. male. However, gender for a linguist is a grammatical classification, which may be quite independent of any classification.

Em quase todas as línguas conhecidas, há distinção de gênero como classe nominal: masculino e feminino, em Português, masculino, feminino e neutro em Alemão, etc. Em Yaathe, a língua que focalizamos aqui, por exemplo, há gênero gramatical nas classes nome e adjetivo e na classe de pronomes. Nessa última, diferente do que mais comumente se encontra nas línguas do mundo, que é uma oposição masculino vs. feminino apenas na terceira pessoa; em Yaathe, a oposição ocorre em todas as pessoas do singular, como mostramos abaixo.

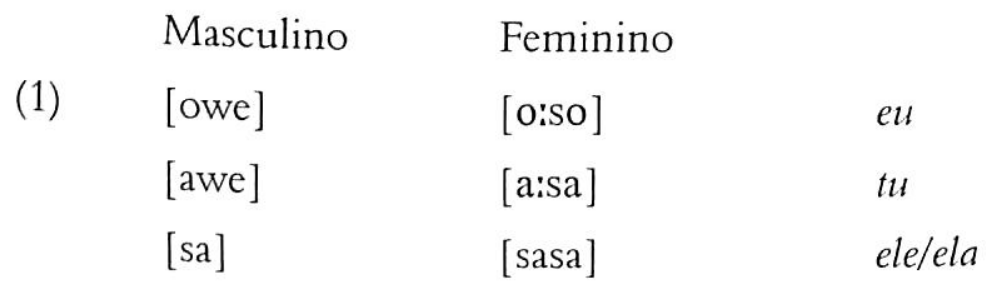

Distinção de gênero como classe nominal, gênero propriamente dito ou gênero gramatical, não corresponde diretamente a diferenças de sexo, ao passo que, no caso de dêixis de gênero, a língua de homens e mulheres aponta diretamente para o sexo do falante e/ou do ouvinte. Em relação aos marcadores de gênero, encontrados em usos discursivos, a diferença encontra-se no fato de que marcadores de gênero são variáveis sociolinguísticas, como propostas por Labov (1972), construídas socialmente. Essas variáveis, ao contrário dos morfemas lexicais e gramaticais, não são formas fixas nem segmentáveis. Por exemplo, uma variável investigada por Labov em seu estudo de Nova Iorque foi a variável realização da consoante inicial em palavras como there. A pronúncia dessa consoante em Nova Iorque varia entre a forma padrão [ð] e a 
forma não-padrão [d]. Os dados de Labov foram reanalisados por Horvath (1985), que mostra que uma ocorrência mais alta da pronúncia padrão [ð] está mais associada às mulheres do que aos homens. Por exemplo, 100 por cento de mulheres da classe média usava a pronúncia [ð], contra 69 por cento de homens e 80 por cento de homens da classe trabalhadora e da classe mais baixa. Fica claro, então, que uma ocorrência alta da pronúncia é um marcador de gênero para mulheres na cidade de Nova Iorque, especialmente para mulheres da classe média (FOLLEY, 1997, p. 301).

O outro tipo de distinção entre gêneros, comumente tratada como índice de fala masculina e fala feminina, é o que estamos chamando de dêixis de gênero, "(...) in which some actual linguistic elements are indexicals of some fact about gender, maybe that of the speaker or that of the addressee, or both" (FOLLEY, 1997, p. 299). Esse tipo de distinção tem sido atestado pelo menos desde o século XVI, quando os conquistadores espanhóis do Novo Mundo comentaram, com um certo exagero, que os nativos das ilhas do Caribe tinham línguas distintas para homens e mulheres. É desse tipo uma das distinções de gênero que encontramos em Yaathe e que devemos descrever suscintamente neste artigo.

\section{Dêixis de gênero em algumas línguas indígenas brasileiras}

Parece certo que quase todas as línguas do mundo estabelecem distinção entre fala feminina e fala masculina, principalmente no léxico, normalmente havendo duas formas distintas para se designar o mesmo objeto, de acordo com se o falante, o ouvinte ou a terceira pessoa é homem ou mulher.

Nas línguas indígenas brasileiras, essa distinção vem sendo observada bastante regularmente. No trabalho de Borges (2004), encontramos a sua descrição do fenômeno em cinco línguas pertencentes a diferentes troncos e famílias linguísticas: Kamaiurá (Tupi-Guarani); Karajá (Tronco Macro-Jê e Família Karajá); 
Kokáma (Família Tupi-Guarani); Pirahã (Família Múra); e Xavante (Família Jê).

Nessas línguas, a oposição fala feminina vs. fala masculina se manifesta em diferentes níveis de análise, do fonético ao discursivo. Kamaiurá, por exemplo, tem posposições diferentes para homens e mulheres (SEKI, 2000, em BORGES, 2004); em Karajá, a distinção é marcada no nível fonológico, apresentando diferenças com relação à estrutura da sílaba; Kokáma apresenta formas especiais de pronomes para homens e mulheres e ainda possui diferenças fonéticas (BALMORI, 1967, em BORGES, 2004); na língua Pirahã, a distinção de fala entre homens e mulheres também é fonética; e em Xavante uma parte do léxico, como pronomes indefinidos e interrogativos e advérbios, possuem formas diferentes para homens e mulheres.

Como bem conclui Borges (2004, p. 112), a diferença entre fala masculina e fala feminina não é um fenômeno exótico, desde que é encontrado em muitas línguas do mundo, como, por exemplo, no Japonês. Além das línguas apresentadas no trabalho de Borges, há notícia de muitas outras línguas indígenas que realizam a distinção. Mais uma dessas línguas, de que se tem notícia, é Aweti, uma língua do tronco Tupi (BORELLA, 2000).

Na língua Ofayé, uma língua do tronco Macro-Jê, a distinção não é muito evidente, mas há vestígios no discurso dos falantes de que é possível que ela exista ou tenha existido, dado que a língua encontra-se em um estágio em que tem recebido muita influência externa, tanto das outras línguas indígenas que convivem na aldeia Ofayé (Caiuá, Guarani) como, e principalmente, do Português. Sobre uma alternação no nível morfológico, para a qual não foi encontrada uma explicação fonológica ou lexical, uma falante Ofayé informou que uma das variantes "são os homens que falam assim" (OLIVEIRA, em prep.). 


\section{A língua Yaathe}

A língua Yaathe é falada pelos índios Fulni-ô que vivem no município de Águas Belas, Sudoeste do Estado de Pernambuco, na Região Nordeste do Brasil.

Os Fulni-ô são o único povo indígena dessa região ${ }^{1}$ que preservou a língua original, falada pelos seus antepassados, os rituais religiosos e muitos outros elementos do seu equipamento cultural. A sociedade Fulni-ô tem sua identidade étnica preservada e definida a partir da língua e da religião.

A língua Yaathe, classificada geneticamente como sendo Macro-Jê (RODRIGUES, 1986), mas sem uma relação direta de família com nenhuma outra língua conhecida também pertencente ao Tronco Macro-Jê e, por isso, sendo considerada língua isolada, é falada pela maior parte da população Fulni-ô. Costa (1993), em um estudo que definiu o perfil lingüístico da comunidade Fulni-ô, demonstra que $91,5 \%$ da população é falante ativa ou passiva da língua Yaathe, que ela definiu como sendo a língua materna do grupo, embora sujeita a certas regras de uso, condicionadas sociolinguisticamente pelo fator faixa etária que, por șua vez, é usado para constituir grupos pares no sentido laboviano do termo.

A distinção de gênero, que marca fala masculina vs. fala feminina, conforme temos definido acima, é um aspecto da estrutura linguística do Yaathe que não foi ainda contemplado em nenhum dos trabalhos de descrição da língua já efetuados. Podemos constatar essa lacuna nos trabalhos dos seguintes pesquisadores: Lapenda (1968); Meland (1969); e Costa (1999), bem como em toda uma série de ensaios e artigos já publicados sobre a língua.

Ao fazermos esta afirmação, estamos deixando de fora o Estado do Maranhão que, embora politicamente incluído na Regiāo Nordeste, apresenta características geográficas, climáticas e históricas bastante diferentes das encontradas nos demais estados nordestinos. 
Diante disso, resolvemos dar uma breve notícia do fenômeno, com alguns exemplos, enquanto preparamos uma descrição mais detalhada. Neste artigo, estamos utilizando dados de intuição de uma das autoras, que é índia Fulni-ô.

\section{A expressão da dêixis de gênero em Yaathe}

A expressão da dêixis de gênero em Yaathe foi encontrada em formas lexicais - palavras - e na morfologia - em sufixos.

\subsection{Expressão lexical}

Observamos que algumas distinções realizam-se pelo uso de itens lexicais diferentes por homens e mulheres. Em diferentes classes de palavras, esses itens distintos foram encontrados.

1) conectores

Duas formas diferentes foram encontradas para os seguintes conectores.

a) contra-expectativa (adversativo)

Fala masculina Fala feminina

(2) [kõnefãw] [kõnefasa] mas, porém

A diferença sendo fonética, desde que talvez se pudesse isolar o material fonético responsável pela diferença de forma, parecenos, entretanto, que não devemos, neste ponto da investigação, propor tal solução, desde que a análise morfológica da língua não tem nos mostrado uma realização sistemática, em contextos fixos, desses elementos. 
b) conclusão

Fala masculina

(3) [neskedina]
Fala feminina

[neskedudina] assim, desse modo

Do mesmo modo que no item anterior, a distinção poderia ser estabelecida em termos fonéticos, pois a forma usada pelas mulheres apresenta material a mais em relação à forma usada pelos homens. Não temos, porém, como atribuir a esse material adicional um significado que lhe possa garantir o status de morfema gramatical. Isso posto, preferimos, por enquanto, incluir as duas formas no léxico.

2) agradecimento

Fala masculina

Fala feminina

(4)

[keKafo]

$\left[\right.$ jajop $^{\mathrm{h}}$ ]

obrigado/obrigada

3) interjeição

Fala masculina

Fala feminina

(5) [ateeka]

[atesõ:k ${ }^{\mathrm{j}} \mathrm{a}$ ]

que saudade!

As palavras de agradecimento e a interjeição são claramente formas lexicais diferentes. É claro que, por comparação puramente fonética, podemos pensar que há uma série de morfemas em ambas as formas, com a forma usada pelas mulheres, no caso da interjeição, parecendo mais complexa morfologicamente. Contudo, não é possível identificar, como já dissemos, de uma forma sistemática, os morfemas que marcam a distinção fala masculina vs. fala feminina. Essa identificação de morfemas, porém, torna-se possível quando observamos formas verbais. Na próxima secção, apresentaremos alguns desses casos. 
De um modo bastante interessante, e que mostra que a distinção é funcional, no sentido de que está sendo usada regular e sistematicamente, um falante masculino recusou-se a falar a forma [jajop $\left.{ }^{\mathrm{h}}\right]$, quando lhe pedimos que a dissesse apenas para que a lingüista pudesse usá-la em uma determinada situação. A recusa cm ensinar a palavra agradecer foi explicada pelo falante com o seguinte enunciado: "eu não sou mulher". O fato parece ainda um pouco mais interessante se informarmos que o dito falante masculino era uma criança, de aproximadamente seis anos.

\subsection{Expressão morfológica ${ }^{2}$}

Yaathe apresenta uma série de modos verbais e formas participiais. No trabalho de Costa (1999), podemos ver que a língua tem três modos verbais principais - indicativo, subjuntivo e imperativo - que se desdobram em outros subtipos, e cinco formas participiais.

A língua marca o modo indicativo ${ }^{3}$, na morfologia verbal, por um sufixo que apresenta a seguinte série de alomorfes: [-ka],

\footnotetext{
As abreviaturas utilizadas nesta seção são as seguintes: 3SG.AG - terceira pessoa do singular, sujeito agente; FM - fala masculina; FF - fala feminina; CONT continuativo; VER - verbalizador; PART.PRES - particípio presente; $1 S G$ - primeira pessoa do singular; $2 \mathrm{SG}$ - segunda pessoa do singular; IMP - modo imperativo.

Uma interpretação diferente da fornecida por Costa (1999) para o sufixo [-ka] é que ele nāo seria um morfema de modo indicativo, mas um verbalizador. Un argumento para dar suporte a essa proposta vem da observaçāo de que ele pode ser omitido na fala sem que isso altere o significado de indicativo do enunciado. $O$ indicativo sendo o modo não marcado, $[-\varnothing]$ poderia ser a sua forma. Nos modos marcados, como subjuntivo e imperativo, o sufixo que marca esses modos dispensaria a presença do verbalizador. Podemos ainda considerar o fato de que verbos inativos, como os que constituem predicados nominais, podem tornar-se ativos apenas por receberem o morferma [-ka], o que seria mais um argumento para levar-nos a considerar esse morfema um verbalizador em vez de uma expressāo de modo indicativo. Neste trabalho, para podermos explicar alguns casos de co-ocorrência do sufixo [-ka] com o sufixo[-te], que marca particípio presente, consideraremos que o primeiro desses morfemas é um verbalizador.
} 
$\left[-\mathrm{k}^{\mathrm{j}} \mathrm{a}\right],\left[-\mathrm{k}^{\mathrm{w}} \mathrm{a}\right]$. Essas alomorfias são criadas por processos morfofonológicos que ocorrem na língua e que estão descritos em Costa (1999). Para os nossos objetivos neste trabalho, não precisamos entrar nos detalhes desses processos. Basta-nos informar que a distinção entre fala de homens e fala de mulheres foi encontrada na forma de indicativo, sendo marcada por um sufixo $[-n e]$.
a) formas do indicativo

Fala masculina

Fala feminina

(6) [ta samakehle]

/ta samake-hele-ø/

3SG.AG casar-IM-FM

[ta samakehlẽne]

elelela já casou (homem)

/ta samake-hele-ne/

3SG.AG casar-PF-FF

elelela já casou (mulher)

(7) [nãnukã:k $\left.{ }^{j} a t e\right]$

[nãnukã:k ${ }^{\mathrm{j}}$ atene ]

/nanu-kane-ka-te-ø/

/nanu-kane-ka-te-ne/

dizer-CONT-VER-PART.PRES-FM

dizer-CONT-VER-PART.PRES-FF

(eu) ainda estou dizendo (homem) (eu) ainda estou dizendo (mulher)

(8) [djokahle]

/i o-ka-hele-ø/

[djokahlẽne]

1SG ir-VER-IM-FM

/i

o-ka-hele-ne/

1SG ir-VER-IM-FF

eu já vou

eu já vou

b) formas do imperativo

A forma básica do modo imperativo em Yaathe é constituída pelo pronome sujeito de segunda pessoa (singular ou plural), pela 
raiz verbal sem qualquer morfologia e pelo morfema de imperativo, que é [-Si]. O pronome sujeito, entretanto, em fala espontânea, pode ser omitido. O alomorfe [-كo], que podemos observar nos exemplos que apresentamos abaixo, é o resultado de um processo de harmonia vocálica que opera na língua, selecionando determinados morfemas. Caracteriza-se, pois, como um processo que se aplica ainda no nível lexical. Para maiores informações, ver Costa (1999).

No modo imperativo, os morfemas que marcam a dêixis de gênero são $[-\varnothing]$ para a fala masculina e [-na] para a fala feminina.

Fala masculina

(9) [aofo]

/a

2SG vir-IMP-FM

venha! (homem)

(10) $[\mathrm{koso}]$

/ko- $\int \mathrm{o}-\varnothing /$

dar-IMP-FM

dê! (homem)
Fala feminina

[aofina]

/a o- i-na/

1SG vir-IMP-FF

venha! (mulher)

[kofina]

/ko-Si-na/

dar-IMP-FF

dê! (mulher)

Existe uma terceira forma para esses enunciados imperativos: [ahnã] e [kohnã]. Assim, temos um jogo interessante nessa distinção de três termos divididos pelos dois sexos. Enquanto as formas [aofo] e [kofo] podem ser usadas somente pelos homens, as formas [ahnã] e [kohnã] podem ser usadas pelos dois sexos indiferentemente. Além disso, aos homens também é permitido utilizar as formas de fala feminina.

Essa situação, em que aos homens é dada uma maior mobilidade entre os usos lingüísticos, parece ser bastante difundida 
através das culturas. Há, na literatura sobre o tema, diversos casos em que as formas masculinas são restritas a situações em que os destinatários são exclusivamente homens, enquanto as formas femininas são usadas em qualquer situação, como, por exemplo, em Yana (SAPIR, 1949). Também podem-se encontrar sistemas que funcionam de um jeito mais complexo, como em Kūrux (EKKA, 1972), na qual as formas marcam díades do mesmo sexo, homem para homem e mulher para mulher, mas as formas masculinas são usadas com díades de sexos diferentes, de modo geral (FOLLEY, 1997, p. 300).

Note-se, porém, que a distinção fala feminina vs. fala masculina, como expressa nos exemplos do Yaathe apresentados acima, é a mais corrente, a mais aceita e a mais facilmente elicitável. As outra formas de uso são apenas esporadicamente encontráveis, em situações específicas que precisam ser investigadas para uma descrição mais completa, considerando-se outros aspectos da comunicação e da interação sócio-cultural existentes na comunidade de fala. Para tal empreendimento, parece ser necessário o uso de instrumentos de investigação fornecidos por áreas como a sociolinguística interacional e a etnografia da fala.

\section{Conclusão}

O que pretendemos fazer neste artigo foi tentar justificar como uma abordagem funcionalista da linguagem pode ajudar no trabalho de descrição lingüística, desde que essa linha de investigação permite ao lingüista descritivista não apenas descobrir os elementos formais que constituem a língua - fonemas, morfemas, sentenças - mas ainda investigar como as formas linguísticas são usadas na comunidade de fala para expressar, além do significado dos itens lingüísticos, os significados sociais, as intenções, o que nada mais é, afinal de contas, do que uma análise do uso da linguagem. 
Desse ponto de vista, uma apresentação, ainda que preliminar, da expressão de um fenômeno lingüístico como a dêixis de gênero serve para ilustrar a pressuposição teórica exposta no início deste artigo. Fora isso, outra finalidade que tínhamos em mente ao elaborarmos este ensaio foi a de dar a notícia sobre a existência do fenômeno descrito na língua Yaathe, da qual, apesar de tanto haver sido descrita, isso ainda não havia sido dito.

\section{Referências}

BALMORI, C. H. Estudos de área linguística indígena. Buenos Aires: Universidad de Buenos Aires, Bucca, 1967.

BORELLA, C. C. Aspectos morfossintáticos da língua Aweti (Tiupi). Dissertação (Mestrado) - Instituto de Estudos da Linguagem, Universidade Estadual de Campinas, Campinas-SP, 2000.

BORGES, M. V. Diferenças entre as falas feminina e masculina no Karajá e em outras línguas brasileiras: aspectos tipológicos. Liames 4, Campinas: IEL/UNICAMP, 2004. p. 103-114.

COSTA, J. F. Bilingiiismo e atitudes lingiuisticas interétnicas. Aspectos do contato Português-Ya:thê. Dissertação (Mestrado), Universidade Federal de
Pernambuco, Recife, 1993 . Pernambuco, Recife, 1993.
COSTA, J. F. Yaathe, a última língua nativa no Nordeste do Brasil. Aspectos
morfo-fonológicos e morfo-sintáticos. Tese (Doutorado), Universidade Federal
de Pernambura, Recife, 1999 . de Pernambuco, Recife, 1999.

EKKA, F. Men's and women's speech in Kurux. Linguistics, 81, p. 25-31,
1972.

FOLLEY, W. A. Anthropological linguistics. An introduction. Oxford: Blackwell, 1997. 
HORVATH, B. Variation in Australian English: The sociolects of Sydney. Cambridge: Cambridge University Press, 1985.

LABOV, W. Sociolinguistic Patterns. Philadelphia: University of Pennsylvania Press, 1972.

LAPENDA, G. Estrutura da língua Iatê. Recife: UFPE, 1968.

MELAND, D. Fulni-ô grammar, Arquivo lingïístico, n. 026. Brasília, D. F: Summer Institute of Linguistics, 1969.

OliveIrA, M. D. (em prep.). Fonologia e Gramática do Ofayé. Tese (Doutorado em Lingüística) - Programa de Pós-graduação em Letras e Lingüística, Universidade Federal de Alagoas, Maceió.

PAYNE, E. T. Describing morphosyntax. A guide for field linguists. Cambridge: Cambridge University Press, 1997.

RODRIGUES, A. D. Línguas brasileiras. Para o conhecimento das línguas indígenas. São Paulo: Loyola, 1986.

SAPIR, E. Conceptual categories in primitive languages. In Hymes, D. (Ed.), Language in culture and society: a reader in linguistics and anthropology. New York: Harper and Row, 1964.

SAUSSURE, F. Curso de lingüística geral. São Paulo, Cultrix, 1916.

SEKI, L. Gramática do Kamaiurá, língua Tupi-Guarani do Alto Xingu. Campinas: Editora da Unicamp; São Paulo: Imprensa Oficial, 2000. 